
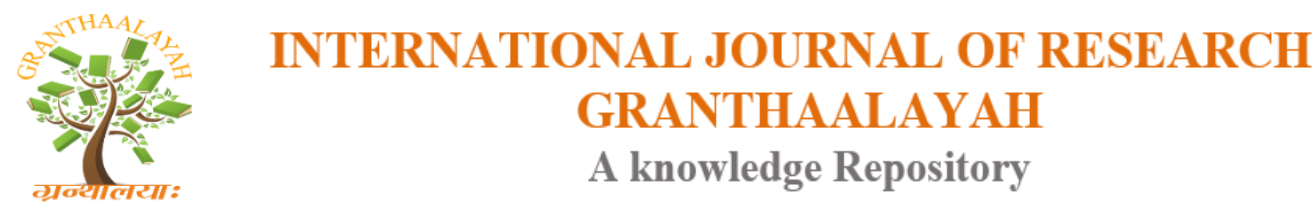

Science

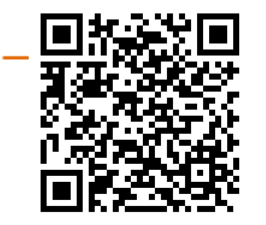

\title{
REDUCTION OF ACTIVE POWER LOSS BY IMPROVED TABU SEARCH ALGORITHM
}

\author{
Dr.K. Lenin *1 \\ ${ }^{* 1}$ Professor, Department of EEE, Prasad V.Potluri Siddhartha Institute of Technology, Kanuru, \\ Vijayawada, Andhra Pradesh, India
}

\begin{abstract}
In this paper, an Improved Tabu Search (ITS) algorithm has been proposed to solve the optimal reactive power problem. In this work Tabu Search- has been hybridized with Simulated Annealing algorithm to solve the optimal reactive power problem. Hybridization of these two algorithms improves the exploration \& exploitation capabilities during the search. Proposed Improved Tabu Search (ITS) algorithm has been tested in Standard IEEE 57,118 bus systems \& real power loss has been comparatively reduced with voltage profiles are within the limits.
\end{abstract}

Keywords: Tabu Search; Simulated Annealing; Reactive Power Problem; Transmission Loss.

Cite This Article: Dr.K. Lenin. (2018). "REDUCTION OF ACTIVE POWER LOSS BY IMPROVED TABU SEARCH ALGORITHM." International Journal of Research - Granthaalayah, 6(7), 1-9. https://doi.org/10.29121/granthaalayah.v6.i7.2018.1277.

\section{Introduction}

Optimal reactive power problem is key problem in secure \& economic operations of power system. The sources of the reactive power are the generators, synchronous condensers, capacitors, static compensators and tap changing transformers. The problem that has to be solved in a reactive power optimization is to determine the required reactive generation at various locations so as to optimize the objective function. Here the reactive power dispatch problem involves best utilization of the existing generator bus voltage magnitudes, transformer tap setting and the output of reactive power sources so as to minimize the loss and to enhance the voltage stability of the system. It involves a non linear optimization problem. Various mathematical techniques have been adopted to solve this optimal reactive power dispatch problem. These include the gradient method [1-2], Newton method [3] and linear programming [4-7]. The gradient and Newton methods suffer from the difficulty in handling inequality constraints. To apply linear programming, the input- output function is to be expressed as a set of linear functions which may lead to loss of accuracy. Recently Global Optimization techniques such as genetic algorithms have been proposed to solve the reactive power flow problem [8,9]. This paper proposes an Improved Tabu Search (ITS) algorithm has been proposed to solve the optimal reactive power problem. In this work Tabu Search- has been hybridized with Simulated Annealing algorithm to solve the optimal reactive power problem. 
Hybridization of these two algorithms improves the exploration \& exploitation capabilities during the search. Proposed Improved Tabu Search (ITS) algorithm has been tested in Standard IEEE 57,118 bus systems \& real power loss has been comparatively reduced with voltage profiles are within the limits.

\section{Problem Formulation}

\section{Active Power Loss}

The objective of the reactive power dispatch is to minimize the active power loss in the transmission network, which can be described as follows:

$F=P L=\sum_{k \in N b r} g_{k}\left(V_{i}^{2}+V_{j}^{2}-2 V_{i} V_{j} \cos \theta_{i j}\right)$

Where F- objective function, $\mathrm{P}_{\mathrm{L}}$ - power loss, $\mathrm{g}_{\mathrm{k}}$-conductance of branch, $\mathrm{Vi}$ and $\mathrm{V}_{\mathrm{j}}$ are voltages at buses $\mathrm{i}, \mathrm{j}, \mathrm{Nbr}$ - total number of transmission lines in power systems.

\section{Voltage Profile Improvement}

For minimizing the voltage deviation in PQ buses, the objective function becomes:

$F=P L+\omega_{v} \times V D$

Where VD - voltage deviation, $\omega_{v^{-}}$is a weighting factor of voltage deviation.

Voltage deviation given by:

$V D=\sum_{i=1}^{N p q}\left|V_{i}-1\right|$

Where Npq- number of load buses

\section{Equality Constraint}

The equality constraint of the problem is represented by the power balance equation, where the total power generation must cover the total power demand and the power losses:

$P_{G}=P_{D}+P_{L}$

Where $\mathrm{P}_{\mathrm{G}^{-}}$total power generation, $\mathrm{PD}$ - total power demand.

\section{Inequality Constraints}

The inequality constraints in the power system as well as the limits created to ensure system security. Upper and lower bounds on the active power of slack bus (Pg), and reactive power of generators $\left(\mathrm{Q}_{\mathrm{g}}\right)$ are written in mathematically as follows:

$$
\begin{aligned}
& P_{\text {gslack }}^{\min } \leq P_{\text {gslack }} \leq P_{\text {gslack }}^{\max } \\
& Q_{g i}^{\min } \leq Q_{g i} \leq Q_{g i}^{\max }, i \in N_{g}
\end{aligned}
$$


Upper and lower bounds on the bus voltage magnitudes $\left(\mathrm{V}_{\mathrm{i}}\right)$ :

$V_{i}^{\min } \leq V_{i} \leq V_{i}^{\max }, i \in N$

Upper and lower bounds on the transformers tap ratios $\left(\mathrm{T}_{\mathrm{i}}\right)$ :

$T_{i}^{\min } \leq T_{i} \leq T_{i}^{\max }, i \in N_{T}$

Upper and lower bounds on the compensators reactive powers $\left(\mathrm{Q}_{\mathrm{c}}\right)$ :

$Q_{c}^{\min } \leq Q_{c} \leq Q_{C}^{\max }, i \in N_{C}$

Where $\mathrm{N}$ is the total number of buses, $\mathrm{N}_{\mathrm{T}}$ is the total number of Transformers; $\mathrm{N}_{\mathrm{c}}$ is the total number of shunt reactive compensators.

\section{Tabu Search}

Tabu search (TS), which was firstly developed by Glover [10-12]. Neighbourhood explorations take a potential solution to a problem and authenticate its instantaneous local opportunities, which is, solutions that are similar except for one or two minor details to recognize a better-quality solution. Local search methods incline to become stuck in suboptimal regions. Tabu search takes benefit of the performance of these approaches by using memory structures, which elucidate the visited solutions. If a potential solution has been already visited within a certain short-term period or if it has already violated a rule, it is marked as "tabu" (forbidden) so that the algorithm would not reconsider that possibility.

1) Arbitrarily develop an initial solution

2) Calculate neighbourhood

3) Choose a candidate move

4) Is candidate tabu? If yes then go to step 4 a or go to step 5

4a. Will solution be the absolute best? Or go to step $4 \mathrm{~b}$

4b. Reject candidate move and adjust the neighbourhood then go to step 3 .

5) Update solution by incorporating the candidate move, set $\mathrm{z}$ value

6) Have we reached the stopping criteria?

$6 a$. if yes -Stop and report the best solution found during search

6b. if no - go to step 2.

\section{Tabu Search Algorithm}

Step 1. Let $\mathrm{S}$ be the preliminary feasible solution and $\mathrm{Z}$ its objective function value; then, set $\mathrm{S}^{*}=$ $\mathrm{S}$,

$Z^{*}=\mathrm{Z}$, max short-term memory $(\mathrm{STM})=5$, and $\max$ iteration $=1,000$; iter $=1$. Best $\mathrm{O}$ value $=\mathrm{O}$ value.

Step 2. Arbitrary $(i, j)=$ rand/Long-term memory $($ LTM $)(i, j),(n 1, n 2)=$ the indices of maximum value in arbitrary.

Step 3. If there is none (n1, n2) in STM matrix, alter n1 and n2 locations; or else, repeat step 2. 
Step 4. Inset $\mathrm{n} 1$ and $\mathrm{n} 2$ in STM and release the last indices from STM (e.g., m1, m2); and LTM $(\mathrm{m} 1, \mathrm{~m} 2)=\operatorname{LTM}(\mathrm{m} 1, \mathrm{~m} 2)+1$.

Step 5. Compute the objective function value $(Z)$ of the new permutation.

Step 6. If $Z \leq Z^{*}$, then $Z^{*}=Z, S^{*}=S$, and iter $=$ iter +1 .

Step 7. If iter $\leq \max$ iteration, then replicate step 2; or else, print $Z^{*}$ and $S^{*}$.

\section{Simulated Annealing}

Simulated annealing (SA) is a standard probabilistic metaheuristic for combinatorial optimization problem of locating a good guesstimate to the global optimum of a given function in an attractive great exploration space. For certain problems, SA may be more efficient than exhaustive enumeration rather than the best possible solution. Paul et al [13] reported that for a number of varied problem instances, SA could perform better for higher quality targets while TS performs better for lower quality targets.

1) Set initial temperature; arbitrarily develop an initial solution

2) Arbitrarily choose unit and period of harvest to change in current solution

3) Is proposed solution better than current solution?

3a. If yes- Then iterations $=$ iterations +1 ; total iterations $=$ total iterations +1

3b. If no- then Calculate acceptance value- if solution accepted, Then move to step 3a or go to step 2.

4) Current solution $=$ proposed solution

5) Is Time to change temperature?

5a. if yes then - New temperature $=$ old temperature $\mathrm{x}$ temperature reduction factor

5 b. if no then go to step - 2

6) Have we reached the stopping criteria?

$6 a$. if yes - Stop and report the best solution found during search

6 b. if no - go to step 2

\section{Simulated annealing algorithm}

$\mathrm{S} \leftarrow$ Create Initial Solution ( )

$\mathrm{T} \leftarrow \mathrm{T}_{0}$

While end conditions not met do

$s^{\prime} \leftarrow$ Pick At Arbitrary (N(s))

if $\left(\mathrm{f}\left(s^{\prime}\right)<\mathrm{f}(\mathrm{s})\right)$ then

$s \leftarrow s^{\prime}$

Else

Admit $s^{\prime}$ as new-fangled solution with possibility $\mathrm{p}\left(\mathrm{T}, s^{\prime}, s\right)$

End if

Modernize (T)

End while 


\section{Hybridized Tabu Search - Simulated Annealing Algorithm for Solving Optimal Reactive Power Problem}

Both the simulated annealing and tabu search algorithms has been hybridized. Step 1 to step 6 main part of hybridization to handle the reactive power problem.

\section{step1:}

Set $\mathrm{S}$ as preliminary solution and $\mathrm{z}$ - evaluate objective function

step1. 3: $S^{*}=S$ and $Z^{*}=Z$;

$\mathrm{STM}=5 ; / /$ max short-term memory

Max iteration $=1000$; iter $=1$; best value $\mathrm{O}=\mathrm{O}$ value

step2: randomize

step2.1: for $\mathrm{i}=1$ to $\mathrm{n}$ do

for $\mathrm{j}=1$ to $\mathrm{n}$ do

ARBITRARY $(i, j)=$ rand/LTM;

step2.2: $(\mathrm{i}, \mathrm{j})$ and $(\mathrm{n} 1, \mathrm{n} 2)=\mathrm{index}$ of $(A R B I T R A R Y \in \mathrm{STM})$;

step3: $\mathrm{T}=0$;

for $\mathrm{i}=1$ to size $(\mathrm{STM}, 1)$ do

for $\mathrm{j}=1$ to size $(\mathrm{STM}, 2)$ do;

if $((\mathrm{n} 1, \mathrm{n} 2)==\operatorname{STM}(\mathrm{i}, \mathrm{j}))$

$\mathrm{T}=1$; reiterate Step 2

if $(\mathrm{T}=0)$

\{

temp $=\mathrm{n} 1$;

$\mathrm{n} 1=\mathrm{n} 2$;

$\mathrm{n} 2=$ temp

\}

Step 4:

$\mathrm{m} 1=\operatorname{size}(\mathrm{STM}, 1)$;

$\mathrm{m} 2=$ size (STM,2);

$(\mathrm{n} 1, \mathrm{n} 2)=\operatorname{STM}(\mathrm{m} 1, \mathrm{~m} 2)$;

$\operatorname{LTM}(\mathrm{m} 1, \mathrm{~m} 2)=\mathrm{LTM}(\mathrm{m} 1, \mathrm{~m} 2)+1$;

step5: $\mathrm{z}=$ calculate objective function;

step 6 :

if $\left(\mathrm{z}<=\mathrm{z}^{*}\right) ; \mathrm{z}^{*}=\mathrm{z}$

\{

$\mathrm{S} *=\mathrm{S}$;

iter=iter+1

\}

step7: if (iter $<=$ max iteration) ; repeat step 2 ; else print $\mathrm{z}^{*}$ and $\mathrm{S}^{*}$

\section{Simulation Results}

At first Improved Tabu Search (ITS) algorithm has been tested in standard IEEE-57 bus power system. The reactive power compensation buses are 18, 25 and 53. Bus 2, 3, 6, 8, 9 and 12 are PV buses and bus 1 is selected as slack-bus. The system variable limits are given in Table 1. 
The preliminary conditions for the IEEE-57 bus power system are given as follows:

$\mathrm{P}_{\text {load }}=12.102$ p.u. Qload $=3.014$ p.u.

The total initial generations and power losses are obtained as follows:

$\sum P_{G}=12.408$ p.u. $\sum Q_{G}=3.3142$ p.u.

$\mathrm{P}_{\text {loss }}=0.25826$ p.u. Q Q loss $=-1.2038$ p.u.

Table 2 shows the various system control variables i.e. generator bus voltages, shunt capacitances and transformer tap settings obtained after optimization which are within the acceptable limits. In Table 3, shows the comparison of optimum results obtained from proposed methods with other optimization techniques. These results indicate the robustness of proposed approaches for providing better optimal solution in case of IEEE-57 bus system.

Table 1: Variable Limits

\begin{tabular}{|c|c|c|c|c|c|c|c|c|c|}
\hline \multicolumn{10}{|c|}{ Reactive Power Generation Limits } \\
\hline Bus no & 1 & 2 & & 3 & 6 & 8 & & 9 & 12 \\
\hline Qgmin & -1.4 & & 15 & -.02 & -0.04 & -1 & & -0.03 & -0.4 \\
\hline Qgmax & 1 & 0. & & 0.4 & 0.21 & 1 & & 0.04 & 1.50 \\
\hline \multicolumn{10}{|c|}{ Voltage And Tap Setting Limits } \\
\hline vgmin & \multicolumn{2}{|c|}{ Vgmax } & \multicolumn{2}{|c|}{ vpqmin } & Vpqma & & \multicolumn{2}{|c|}{ tkmin } & tkmax \\
\hline 0.9 & \multicolumn{2}{|l|}{1.0} & \multicolumn{2}{|c|}{0.91} & 1.05 & & \multicolumn{2}{|c|}{0.9} & 1.0 \\
\hline \multicolumn{7}{|c|}{ Shunt Capacitor Limits } & & & \\
\hline Bus no & \multicolumn{2}{|c|}{18} & \multicolumn{2}{|c|}{25} & \multicolumn{2}{|l|}{53} & & & \\
\hline Qcmin & \multicolumn{2}{|l|}{0} & \multicolumn{2}{|l|}{0} & \multicolumn{2}{|l|}{0} & & & \\
\hline Qcmax & \multicolumn{2}{|l|}{10} & \multicolumn{2}{|c|}{5.2} & \multicolumn{2}{|l|}{6.1} & & & \\
\hline
\end{tabular}

Table 2: Control variables obtained after optimization

\begin{tabular}{|l|l|}
\hline $\begin{array}{l}\text { Control } \\
\text { Variables }\end{array}$ & ITS \\
\hline V1 & 1.1 \\
\hline V2 & 1.032 \\
\hline V3 & 1.036 \\
\hline V6 & 1.022 \\
\hline V8 & 1.020 \\
\hline V9 & 1.002 \\
\hline V12 & 1.010 \\
\hline Qc18 & 0.0660 \\
\hline Qc25 & 0.201 \\
\hline Qc53 & 0.0470 \\
\hline T4-18 & 1.000 \\
\hline T21-20 & 1.040 \\
\hline T24-25 & 0.862 \\
\hline T24-26 & 0.871 \\
\hline T7-29 & 1.054 \\
\hline T34-32 & 0.870 \\
\hline T11-41 & 1.010 \\
\hline T15-45 & 1.031 \\
\hline
\end{tabular}




\begin{tabular}{|l|l|}
\hline T14-46 & 0.912 \\
\hline T10-51 & 1.022 \\
\hline T13-49 & 1.064 \\
\hline T11-43 & 0.912 \\
\hline T40-56 & 0.901 \\
\hline T39-57 & 0.952 \\
\hline T9-55 & 0.952 \\
\hline
\end{tabular}

Table 3: Comparison results

\begin{tabular}{|l|l|l|l|l|}
\hline S.No. & $\begin{array}{l}\text { Optimization } \\
\text { Algorithm }\end{array}$ & Finest Solution & Poorest Solution & $\begin{array}{l}\text { Normal } \\
\text { Solution }\end{array}$ \\
\hline 1 & NLP [14] & 0.25902 & 0.30854 & 0.27858 \\
\hline 2 & CGA [14] & 0.25244 & 0.27507 & 0.26293 \\
\hline 3 & AGA [14] & 0.24564 & 0.26671 & 0.25127 \\
\hline 4 & PSO-w [14] & 0.24270 & 0.26152 & 0.24725 \\
\hline 5 & PSO-cf [14] & 0.24280 & 0.26032 & 0.24698 \\
\hline 6 & CLPSO [14] & 0.24515 & 0.24780 & 0.24673 \\
\hline 7 & SPSO-07 [14] & 0.24430 & 0.25457 & 0.24752 \\
\hline 8 & L-DE [14] & 0.27812 & 0.41909 & 0.33177 \\
\hline 9 & L-SACP-DE [14] & 0.27915 & 0.36978 & 0.31032 \\
\hline 10 & L-SaDE [14] & 0.24267 & 0.24391 & 0.24311 \\
\hline 11 & SOA [14] & 0.24265 & 0.24280 & 0.24270 \\
\hline 12 & LM [15] & 0.2484 & 0.2922 & 0.2641 \\
\hline 13 & MBEP1 [15] & 0.2474 & 0.2848 & 0.2643 \\
\hline 14 & MBEP2 [15] & 0.2482 & 0.283 & 0.2592 \\
\hline 15 & BES100 [15] & 0.2438 & 0.263 & 0.2541 \\
\hline 16 & BES200 [15] & 0.3417 & 0.2486 & 0.2443 \\
\hline 17 & Proposed ITS & 0.22002 & 0.23004 & 0.22268 \\
\hline
\end{tabular}

Then Improved Tabu Search (ITS) algorithm has been tested in standard IEEE 118-bus test system [16]. The system has 54 generator buses, 64 load buses, 186 branches and 9 of them are with the tap setting transformers. The limits of voltage on generator buses are $0.95-1.1$ per-unit., and on load buses are $0.95-1.05$ per-unit. The limit of transformer rate is $0.9-1.1$, with the changes step of 0.025 . The limitations of reactive power source are listed in Table 4 , with the change in step of 0.01 .

Table 4: Limitation of reactive power sources

\begin{tabular}{|l|l|l|l|l|l|l|l|}
\hline BUS & 5 & 34 & 37 & 44 & 45 & 46 & 48 \\
\hline QCMAX & 0 & 14 & 0 & 10 & 10 & 10 & 15 \\
\hline QCMIN & -40 & 0 & -25 & 0 & 0 & 0 & 0 \\
\hline BUS & 74 & 79 & 82 & 83 & 105 & 107 & 110 \\
\hline QCMAX & 12 & 20 & 20 & 10 & 20 & 6 & 6 \\
\hline QCMIN & 0 & 0 & 0 & 0 & 0 & 0 & 0 \\
\hline
\end{tabular}


The statistical comparison results of 50 trial runs have been list in Table 5 and the results clearly show the better performance of proposed Improved Tabu Search (ITS) algorithm in reducing the real power loss.

Table 5: Comparison results

\begin{tabular}{|l|l|l|l|l|}
\hline Active power loss (MW) & $\begin{array}{l}\text { BBO } \\
{[\mathbf{1 7}]}\end{array}$ & $\begin{array}{l}\text { ILSBBO/ } \\
\text { strategy1 } \\
{[\mathbf{1 7}]}\end{array}$ & $\begin{array}{l}\text { ILSBBO/ } \\
\text { strategy1 } \\
{[\mathbf{1 7}]}\end{array}$ & $\begin{array}{l}\text { Proposed } \\
\text { ITS }\end{array}$ \\
\hline Min & 128.77 & 126.98 & 124.78 & 108.48 \\
\hline Max & 132.64 & 137.34 & 132.39 & 114.26 \\
\hline Average & 130.21 & 130.37 & 129.22 & 110.84 \\
\hline
\end{tabular}

\section{Conclusion}

In this paper, an Improved Tabu Search (ITS) algorithm has been successfully solved the optimal reactive power problem. Hybridization of these two algorithms improved the exploration \& exploitation capabilities during the search. In order to evaluate the validity of the proposed Improved Tabu Search (ITS) algorithm, it has been tested on Standard IEEE 57,118 bus systems and simulation results reveal about the good performance of the proposed algorithm in reducing real power loss and voltage profiles are within the limits.

\section{References}

[1] O.Alsac, and B. Scott, “Optimal load flow with steady state security”,IEEE Transaction. PAS -1973, pp. 745-751.

[2] Lee K Y, Paru Y M, Oritz J L -A united approach to optimal real and reactive power dispatch, IEEE Transactions on power Apparatus and systems 1985: PAS-104: 1147-1153

[3] A. Monticelli, M. V.F Pereira, and S. Granville, "Security constrained optimal power flow with post contingency corrective rescheduling", IEEE Transactions on Power Systems: PWRS-2, No. 1, pp.175-182.,1987.

[4] Deeb N, Shahidehpur S.M, Linear reactive power optimization in a large power network using the decomposition approach. IEEE Transactions on power system 1990: 5(2): 428-435

[5] E. Hobson,'Network consrained reactive power control using linear programming, 'IEEE Transactions on power systems PAS -99 (4), pp 868=877, 1980

[6] K.Y Lee, Y.M Park, and J.L Oritz, "Fuel -cost optimization for both real and reactive power dispatches", IEE Proc; 131C, (3), pp.85-93.

[7] M.K. Mangoli, and K.Y. Lee, "Optimal real and reactive power control using linear programming", Electr.Power Syst.Res, Vol.26, pp.1-10,1993.

[8] K. Anburaja, "Optimal power flow using refined genetic algorithm", Electr.Power Compon.Syst, Vol. 30, 1055-1063,2002.

[9] D. Devaraj, and B. Yeganarayana, "Genetic algorithm based optimal power flow for security enhancement", IEE proc-Generation.Transmission and. Distribution; 152, 6 November 2005.

[10] Glover, F. (1986). Future paths for integer programming and links to artificial intelligence. Computers \& Operations Research, 13(5), 533-549.

[11] Glover, F. (1989). Tabu Search - Part 1. ORSA Journal on Computing, 1(2), 190-206.

[12] Glover, F. (1990). Tabu Search - Part 2. ORSA Journal on Computing, 2(1), 4-32.

[13] Paul, G. (2010). Comparative performance of tabu search and simulated annealing heuristics for the quadratic assignment problem. Operations Research Letters, 38(6), 577-581. 
[14] Chaohua Dai, Weirong Chen, Yunfang Zhu, and Xuexia Zhang, "Seeker optimization algorithm for optimal reactive power dispatch," IEEE Trans. Power Systems, Vol. 24, No. 3, August 2009, pp. 1218-1231.

[15] J. R. Gomes and 0. R. Saavedra, "Optimal reactive power dispatch using evolutionary computation: Extended algorithms,” IEE Proc.-Gener. Transm. Distrib. Vol. 146, No. 6. Nov. 1999.

[16] IEEE, "The IEEE 30-bus test system and the IEEE 118-test system", (1993), http://www.ee.washington.edu/trsearch/pstca/.

[17] Jiangtao Cao, Fuli Wang and Ping Li, "An Improved Biogeography-based Optimization Algorithm for Optimal Reactive Power Flow" International Journal of Control and Automation Vol.7, No.3 (2014), pp.161-176

*Corresponding author.

E-mail address: gklenin @ gmail.com 